\title{
Effects of Bacillus subtilis natto on performance and immune function of preweaning calves
}

\author{
P. Sun, J. Q. Wang, ${ }^{1}$ and H. T. Zhang \\ State Key Laboratory of Animal Nutrition, Institute of Animal Science, Chinese Academy of Agricultural Sciences, Beijing 100193, P. R. China
}

\begin{abstract}
The effects of Bacillus subtilis natto on performance and immune function of dairy calves during the preweaning phase were investigated in this study. Twelve Holstein male calves $7 \pm 1 \mathrm{~d}$ of age were randomly allotted to 2 treatments of 6 calves. The Bacillus subtilis natto was mixed with milk and fed directly to the calves. The calves were weaned when their starter intake reached $2 \%$ of their weight. Blood was collected and $\operatorname{Ig} \mathrm{A}, \operatorname{Ig} \mathrm{E}, \operatorname{IgG}, \operatorname{Ig} \mathrm{M}$, and cytokine levels in the serum of all the calves were determined. The results showed that Bacillus subtilis natto increased general performance by improving the average daily gain and feed efficiency and advanced the weaning age of the calves. No difference was observed in serum $\operatorname{IgE}, \operatorname{IgA}$, and IgM, whereas serum IgG was higher in the Bacillus subtilis natto-supplemented calves than in the control calves. Furthermore, calves fed with Bacillus subtilis natto were found to secrete more IFN- $\gamma$, but tended to produce less IL-4 than did the control calves, although serum IL-6 and IL-10 were not affected. This study demonstrated that Bacillus subtilis natto did not stimulate IgE-mediated allergic reactions, but increased serum IgG and IFN- $\gamma$ levels in the probiotic-fed calves. We propose that the viable probiotic characteristics of Bacillus subtilis natto benefit calf immune function.
\end{abstract}

Key words: Bacillus subtilis natto, calf, immune function, performance

\section{INTRODUCTION}

Probiotics are living microorganisms that have been shown to produce no drug resistance or drug residues when direct-fed to human and animals (Holzapfel et al., 2001; Scharek et al., 2005; Guo et al., 2006). As an effective alternative to antibiotics, probiotics have been widely used in the food and feed industries during the past few decades (Solis Pereyra and Lemonnier, 1993; Guo et al., 2006). Probiotics exhibit potential benefits

Received March 15, 2010.

Accepted August 18, 2010.

${ }^{1}$ Corresponding author: jqwangcaas@gmail.com by improving intestinal microbial balance (Fujiwara et al., 2009), promoting intestinal digestion, and increasing animal growth performance (Jenny et al., 1991; Kritas and Morrison, 2005). Recent data have also indicated that some probiotics are efficient immunomodulators, modifying the immune response of T-helper cells 1 and 2 (Th1 and Th2) and thereby enhancing the immune function of the host (Barnes et al., 2007).

With the public's increasing concern regarding the negative effects of antibiotics, many countries have banned or limited the use of antibiotics in animal feeds to reduce the potential production of antibiotic-resistant pathogenic bacteria (Fritts et al., 2000). Therefore, the use of probiotics has gained more attention from researchers. Most of the previous research on probiotics focused on the application of various strains of lactic acid bacteria (Miettinen et al., 1996; Holzapfel et al., 2001). Unlike the lactic acid bacteria, Bacillus species are not normally found in the gastrointestinal tract. However, it has been reported that Bacillus subtilis has the favorable capability of maintaining microflora balance in the gastrointestinal tract and increasing animal performance when administered orally in adequate amounts (Alexopoulos et al., 2004; Kritas and Morrison, 2005). Furthermore, several publications have suggested that $B$. subtilis has an immunostimulating effect (Fiorini et al., 1985) and may promote the secretion of some beneficial vitamins, such as vitamin $\mathrm{K}$ (Yanagisawa and Sumi, 2005; Barnes et al., 2007).

Natto is a traditional food obtained from fermented boiled soybeans. It originates from Japan and possesses a history of more than 1,000 yr. Bacillus subtilis natto is a potential probiotic bacterium cultured from natto, and is a gram-positive spore-forming bacterium (Samanya and Yamauchi, 2002). To date, only a few investigations have been published regarding its beneficial effects in chicken (Inooka, 1988; Fujiwara et al., 2009), but the effects of direct-fed $B$. subtilis natto on the performance and immune responses in dairy calves are still unknown. Consequently, the objective of this study was to investigate the effects of oral administration of B. subtilis natto on preweaning performance, weaning age, and immune function in dairy calves. 
Table 1. Ingredient composition and nutrient levels of starter (DM basis)

\begin{tabular}{lc}
\hline Item & Starter \\
\hline Ingredient, \% & \\
Corn & 38.0 \\
Chinese wildrye & 20.0 \\
Soybean cake & 18.4 \\
Wheat bran & 2.8 \\
Wheat middlings & 7.6 \\
Molasses & 1.6 \\
Oyster shell ground & 1.6 \\
Salt & 0.8 \\
Bentonite & 0.8 \\
Calcium phosphate & 1.2 \\
Extruded soybean & 6.4 \\
Premix ${ }^{1}$ & 0.8 \\
Chemical analysis, ${ }^{2} \%$ & \\
DM & 89.2 \\
CP & 21.2 \\
Ether extract & 5.2 \\
Crude fiber & 32.3 \\
Ash & 4.4 \\
Calcium & 1.2 \\
Phosphorus & 0.6 \\
\hline
\end{tabular}

${ }^{1}$ Premix provided per kilogram of diet: vitamin A, 1,000,000 IU; vitamin D, 270,000 IU; vitamin E, 2,900 IU; Cu, 5,000 mg; Fe, 9,000 mg; $\mathrm{Zn}, 8,000 \mathrm{mg}$; Mn, 6,000 mg; Se, $67 \mathrm{mg}$; I, $227 \mathrm{mg}$; Co, $20 \mathrm{mg}$; Mg, $9,800 \mathrm{mg}$.

${ }^{2}$ Analyzed values.

\section{MATERIALS AND METHODS}

\section{Culture of $B$. subtilis natto}

The B. subtilis natto used in the present study was isolated from fermented soybeans and identified by the State Key Laboratory of Animal Nutrition, Institute of Animal Science, Chinese Academy of Agricultural Sciences. The bacteria were prepared in sterile fermentation medium at $37^{\circ} \mathrm{C}$ for $24 \mathrm{~h}$. The fermentation medium contained $1 \%$ sucrose, $1 \%$ glucose, $2 \%$ soy peptone, $0.4 \% \mathrm{~K}_{2} \mathrm{HPO}_{4}, 0.2 \% \mathrm{KH}_{2} \mathrm{PO}_{4}, 0.05 \% \mathrm{MgSO}_{4}$, and $0.02 \% \mathrm{CaCl}_{2}$. Appropriate dilutions of B. subtilis natto were plated onto fermentation medium plates and incubated at $37^{\circ} \mathrm{C}$ for $24 \mathrm{~h}$ for determination of colonyforming units.

\section{Calves and Diets}

All animals used in this experiment were maintained according to the principles of Chinese Academy of Agricultural Sciences Animal Care and Use Committee. Twelve Holstein bull calves at $7 \pm 1 \mathrm{~d}$ old were randomly divided into 2 treatments. Each treatment had 6 replicates with 1 calf per replicate. The feeding trial was conducted on the research farm of Chinese Academy of Agricultural Sciences. All of the calves were housed in individual pens enclosed with iron fences to avoid cross contamination among calves on the same farm.
Water, concentrate, and dried grass were available ad libitum throughout the feeding period. Starter diet was supplemented to the calves at suckling. All calves were weaned when their starter intake reached $2 \%$ of their weight. Body weight was measured at the beginning and end of the trial and DMI was weighed every $2 \mathrm{~d}$.

The ingredient composition and nutrient levels of the starter are shown in Table 1. The ratio of concentrate:hay in starter diet was 80:20.

\section{Experimental Design and Sample Collection}

Bacillus subtilis natto cultures were mixed with fresh cow milk (1:1, vol/vol) and fed directly to the calves. In the experimental treatment, the calves received a daily dose of no less than $1 \times 10^{10}$ cfu of $B$. subtilis natto in $10 \mathrm{~mL}$ of culture during the a.m. feeding, whereas no additives were fed to the control group. Bacterial concentrations were checked each week to ensure supplementation levels of $10^{9} \mathrm{cfu}$ of viable bacteria/mL.

The experiment ended after the calves were weaned, when blood samples were collected from all of the animals. Seven milliliters of blood was collected in 9-mL Vacutainer tubes (Becton Dickinson Vacutainer Systems, Franklin Lakes, NJ) from the jugular of all the calves. After centrifugation at $3,000 \times g$ for $15 \mathrm{~min}$, the serum was separated and stored at $-20^{\circ} \mathrm{C}$ for later analysis.

\section{Measurement of Serum Antibodies and Cytokines by ELISA}

The determination of serum IgA, IgG, and IgM levels was conducted by ELISA using the cow IgA, IgG, and IgM ELISA kits produced by Bethyl Laboratories (Montgomery, TX). A 96-well microtiter plate (Costar, Corning Inc., Corning, NY) was coated overnight at $4^{\circ} \mathrm{C}$ with capture antibody in carbonate buffer $(\mathrm{pH}$ 7.0), and then PBS containing 1\% Hy-Line Brown layer serum and $0.1 \%$ Tween (ELISA buffer) were added to block the free binding sites for $1.5 \mathrm{~h}$ at $37^{\circ} \mathrm{C}$. Duplicate serum samples were diluted in ELISA buffer and incubated for $2 \mathrm{~h}$ at $37^{\circ} \mathrm{C}$. Thereafter, the plates were incubated with ELISA buffer containing IgA, IgG, or IgM antibodies conjugated with horseradish peroxidase (Serotec, Oxford, UK) for $1 \mathrm{~h}$ at $37^{\circ} \mathrm{C}$. Samples were washed 5 times with PBS containing 0.1\% Tween between each incubation step. The plates were then developed with tetramethylbenzidine to measure the absorbance at 450 $\mathrm{nm}$. The data were expressed as optical density units.

The assessment of serum IgE was performed with the cow ELISA kit (Groundwork Biotechonology Diagnosticate Ltd., San Diego, CA) following manufacturer's instructions. 
Table 2. Effects of Bacillus subtilis natto on preweaning performance and weaning age of probiotic-fed and control calves ${ }^{1}$

\begin{tabular}{lcccc}
\hline & \multicolumn{2}{c}{ Treatment } & & \\
\cline { 2 - 3 } Item & Control & Probiotic & SEM & P-value \\
\hline Initial weight, $\mathrm{kg}$ & 40.0 & 40.1 & 1.74 & 0.98 \\
ADG, $\mathrm{kg} / \mathrm{d}$ & $0.31^{\mathrm{b}}$ & $0.35^{\mathrm{a}}$ & 0.01 & 0.02 \\
Liquid intake, $\mathrm{kg}$ of DM/d & 0.46 & 0.48 & 0.02 & 0.46 \\
Starter intake, $\mathrm{kg}$ of DM/d & 0.33 & 0.28 & 0.02 & 0.14 \\
Total intake, $\mathrm{kg}$ of DM/d & 0.79 & 0.76 & 0.04 & 0.59 \\
Feed efficiency, $\mathrm{kg}$ of DMI/kg of gain & $2.58^{\mathrm{a}}$ & $2.17^{\mathrm{b}}$ & 0.11 & 0.03 \\
Weaning age, d & $58.3^{\mathrm{a}}$ & $51.0^{\mathrm{b}}$ & 2.31 & $<0.05$ \\
\hline
\end{tabular}

${ }^{\mathrm{a}, \mathrm{b}}$ Mean values within a row with different superscripts differ $(P<0.05)$.

${ }^{1}$ Each value is the mean of data from 6 calves per group.

Concentrations of IL-4, IL-6, IL-10, and IFN- $\gamma$ in the serum were measured with the cow ELISA kit (Groundwork Biotechonology Diagnosticate Ltd.) according to the manufacturer's instructions.

\section{Statistical Analysis}

All data were analyzed using the ANOVA procedure of SAS system (version 8.2, SAS Institute Inc., Cary, NC). $P$-values $<0.05$ were considered statistically significant.

\section{RESULTS}

\section{Performance and Weaning Age of the Calves}

The calf performance data for the preweaning period are presented in Table 2. The average daily gain and feed efficiency increased significantly for the calves fed with $B$. subtilis natto throughout the experimental period $(P<0.05)$. No difference was observed in the $\mathrm{DM}$ of liquid or starter intake between the 2 groups. As shown in Table 2, the weaning age of probiotic-fed calves was $51.0 \mathrm{~d}$, which was a week earlier than the control group $(P<0.05)$.

\section{Antibody Levels in the Serum}

To investigate the effects of $B$. subtilis natto on systemic immune response in calves, circulating $\operatorname{IgA}, \operatorname{IgG}$, $\mathrm{IgM}$, and $\mathrm{IgE}$ antibody levels in serum were determined (Table 3). Serum IgA, IgM, and IgE concentrations between control and probiotic-supplemented treatment were not statistically different. Nevertheless, serum IgG was significantly higher $(P<0.05)$ in $B$. subtilis nattosupplemented calves than in the control calves.

\section{Cytokine Concentrations in Calf Serum}

The IL-6 and IL-10 levels were not influenced in the 2 groups throughout the whole experiment (Table 3). Concentrations of IFN- $\gamma$ were higher $(P<0.05)$ in the serum of the calves fed $B$. subtilis natto, whereas IL-4 tended to be lower compared with the control group $(P$ $=0.06)$.

\section{DISCUSSION}

The present study investigated the effects of oral supplementation of B. subtilis natto on dairy calf performance and immune function after assessment of probiotic potential. Previous studies have demonstrated that

Table 3. Effects of Bacillus subtilis natto on $\operatorname{IgA}$, $\operatorname{IgG}$, IgM, IgE, and cytokine concentrations in probiotic-fed and control calves ${ }^{1}$

\begin{tabular}{|c|c|c|c|c|}
\hline \multirow[b]{2}{*}{ Item } & \multicolumn{2}{|c|}{ Treatment } & \multirow[b]{2}{*}{ SEM } & \multirow[b]{2}{*}{$P$-value } \\
\hline & Control & Probiotic & & \\
\hline $\operatorname{IgA}, \mu \mathrm{g} / \mathrm{mL}$ & 42.49 & 45.85 & 4.06 & 0.57 \\
\hline $\mathrm{IgG}, \mathrm{mg} / \mathrm{mL}$ & $3.38^{\mathrm{b}}$ & $4.24^{\mathrm{a}}$ & 0.26 & 0.04 \\
\hline $\mathrm{IgM}, \mathrm{mg} / \mathrm{mL}$ & 3.11 & 3.03 & 0.43 & 0.90 \\
\hline $\mathrm{IgE}, \mathrm{mg} / \mathrm{L}$ & 56.95 & 53.76 & 1.66 & 0.20 \\
\hline \multicolumn{5}{|c|}{ Cytokine concentrations in the serum, $\mathrm{pg} / \mathrm{mL}$} \\
\hline IFN- $\gamma$ & $30.97^{\mathrm{b}}$ & $34.39^{\mathrm{a}}$ & 1.01 & 0.04 \\
\hline IL-4 & 39.32 & 24.17 & 5.00 & 0.06 \\
\hline IL-6 & 183.11 & 192.21 & 7.11 & 0.39 \\
\hline IL-10 & 32.29 & 34.69 & 1.70 & 0.34 \\
\hline
\end{tabular}

${ }^{\mathrm{a}, \mathrm{b}}$ Mean values within a row with different superscripts differ $(P<0.05)$.

${ }^{1}$ Each value is the mean of data from 6 calves per group. 
B. subtilis natto has some antithrombotic and fibrinolytic activity (Omura et al., 2005), and it can be used for the industrial production of levan (Shih et al., 2005) and isolation or purification of vitamin $\mathrm{K}$ (Yanagisawa and Sumi, 2005). Studies in chicken showed that Bacillus subtilis inhibited pathogenic microorganism growth (Fritts et al., 2000; Teo and Tan, 2005), increased digestive enzyme activity, and reduced the yield of ammonia (Samanya and Yamauchi, 2002), which in turn promoted fowl growth performance (Fritts et al., 2000; Teo and Tan, 2005). Consistent with those reports, in the current study, oral supplementation of $B$. subtilis natto increased feed efficiency and the average daily gain of the calves during the experimental period, although milk and starter ingestion was not influenced.

Early weaning is always recommended in the cattle industry to save costs and increase profit. However, early weaning may result in depressed growth performance. Moreover, long-term and excessive ingestion of milk may affect the development of digestive organs. Therefore, consumption of probiotics may be an optimal alternative for preweaning calves. One of the novel findings in the present study is that B. subtilis natto advanced the weaning age of the probiotic-fed calves. Neither milk consumption nor starter feed intake was affected between the probiotic-fed group and the control. The results of our research indicate that oral administration of $B$. subtilis natto before weaning could reduce milking time and positively improve calf growth performance.

One of the most important functions of direct-fed probiotics is that they can play a role in the immune system as immunomodulators. Probiotics by oral administration have been reported to interact with intestinal resident microflora, and epithelial and immune cells; they also trigger and stimulate immune function, leading to antibody production (Tejada-Simon et al., 1999; Fang et al., 2000; Kaburagi et al., 2007). Immunoglobulin $\mathrm{M}$ is the primary antibody produced at the initial stage of antibody response. Immunoglobulin $G$ plays an important role in systemic immune response and is the main antibody in the serum after ingestion of probiotic protein. Immunoglobulin $\mathrm{A}$ is the major antibody in the mucosal immunity, and the main function of IgA is to exert the immune exclusion of pathogenic bacteria by intimate cooperation with innate nonspecific defense mechanisms. In the present study, serum IgG concentration was statistically increased in the probiotic-fed calves compared with the control. Unlike $\operatorname{IgG}$, the concentrations of $\operatorname{IgA}$ and IgM were not influenced by the supplementation of B. subtilis natto, although slight increases in IgA and IgM levels were found in the calves' serum.

Unlike the other immunoglobulins, no difference in $\operatorname{IgE}$ concentration was observed in our results. How- ever, the IgE level in the serum of probiotic-fed calves was a little lower than the control. It is known that $\operatorname{IgE}$ is a sensitive indicator that plays an important role in most food-induced allergies (Ladics et al., 2003), a predominantly Th2-type immune response mediated by IgE. Bacillus subtilis natto is a foreign protein for calves, but our results suggest that $B$. subtilis natto ingestion did not increase $\operatorname{IgE}$ antibody levels in the serum, indicating that B. subtilis natto was not a food allergen for the calves in the current experiment.

Several studies have revealed that B. subtilis spores are capable of enhancing host immunity to prevent some infectious diseases (Novelli et al., 1984; Kosaka et al., 1998). Similar results were obtained by Kosaka et al. (1998), who found that oral administration of B. subtilis spores activated macrophages and natural killer cells in mice. To our knowledge, investigations on the effect of $B$. subtilis natto on the immune function of the mammals are seldom. Only limited publications demonstrated that $B$. subtilis natto increased the numbers of $\mathrm{T}$ and $\mathrm{B}$ lymphocytes (Inooka, 1988; Fujiwara et al., 2009). As has been shown elsewhere, $\mathrm{CD}^{+} \mathrm{T}$ cells, 1 of the $\mathrm{T}$ lymphocyte subsets, are Th cells that can be divided into Th1 and Th2 because of different secretion patterns of cytokines (Carter and Dutton, 1996). Interferon- $\gamma$, the essential cytokine for cell-mediated immunity, is secreted by Th1 lymphocytes, whereas IL-4, IL-6, and IL-10, produced by Th2 lymphocytes predominantly involved in humoral immunity and allergic responses (Carter and Dutton, 1996; He et al., 2005), promote B lymphocytes to proliferate and differentiate into plasma cells, stimulating antibody production and strong antibody-producing responses (Carter and Dutton, 1996).

As noted above, IFN- $\gamma$ is produced not only by activated T cells and NK cells, but also by macrophages and dendritic cells (Frucht et al., 2001). A study conducted by Kosaka et al. (1998) suggested that the activation of macrophages and natural killer cells might be stimulated by IFN. It is generally accepted that IFN- $\gamma$ is the crucial factor predominant in Th1 immune response, and that IFN- $\gamma$ functions reciprocally on the induction of IgE responses (Snapper and Paul, 1987), inhibiting the yield of $\mathrm{IgE}$ and Th2 cytokines. In line with these results, we observed higher concentrations of IFN- $\gamma$, but relatively lower levels of IL- 4 in the serum of probiotic-fed calves. Additionally, no changes were observed in IgE and other Th2 cytokines, such as IL-6 and IL-10, for the probiotic-fed calves.

\section{CONCLUSIONS}

The present study demonstrated that directly feeding B. subtilis natto to calves during the preweaning period increased growth performance by improving average 
daily gain and feed efficiency, as well as by advancing the weaning age of the calves without any adverse effects. The results of our research also prove that oral administration of $B$ subtilis natto does not stimulate IgE-mediated allergic reactions, but does induce the secretion of serum IgG and Th1 cytokine levels, including IFN- $\gamma$, in probiotic-fed calves, which helps to activate immune systems and enhance immunity. This study supports the notion that the viable probiotic characteristics of B. subtilis natto improve growth and benefit the immune function of calves.

\section{ACKNOWLEDGMENTS}

This study was supported financially by the National Basic Research Program (973) of China (Beijing, China; 2011CB100805), the Research Program of the State Key Laboratory of Animal Nutrition [Beijing, China; 2004DA125184 (tuan) 0801], and the Youth Foundation of the Institute of Animal Science, Chinese Academy of Agricultural Sciences (Beijing, China; 2009qn-8).

\section{REFERENCES}

Alexopoulos, C., I. E. Georgoulakis, A. Tzivara, C. S. Kyriakis, A. Govaris, and S. C. Kyriakis. 2004. Field evaluation of the effect of a probiotic-containing Bacillus licheniformis and Bacillus subtilis spores on the health status, performance, and carcass quality of grower and finisher pigs. J. Vet. Med. A Physiol. Pathol. Clin. Med. 51:306-312.

Barnes, A. G. C., V. Cerovic, P. S. Hobson, and L. S. Klavinskis. 2007. Bacillus subtilis spores: A novel microparticle adjuvant which can instruct a balanced Th1 and Th2 immune response to specific antigen. Eur. J. Immunol. 37:1538-1547.

Carter, L. L., and R. W. Dutton. 1996. Type 1 and Type 2: A fundamental dichotomy for all T-cell subsets. Curr. Opin. Immunol. $8: 336-342$.

Fang, H., T. Elina, A. Heikki, and S. Seppo. 2000. Modulation of humoral immune response through probiotic intake. FEMS Immunol. Med. Microbiol. 29:47-52.

Fiorini, G., C. Cimminiello, R. Chianese, G. P. Visconti, D. Cova, T. Uberti, and A. Gibelli. 1985. Bacillus subtilis selectively stimulates the synthesis of membrane bound and secreted $\operatorname{IgA}$. Chemioterapia 4:310-312.

Fritts, C. A., J. H. Kersey, M. A. Motl, E. C. Kroger, F. Yan, J. Si, Q. Jiang, M. M. Campos, A. L. Waldroup, and P. W. Waldroup. 2000. Bacillus subtilis C-3102 (Calsporin) improves live performance and microbiological status of broiler chickens. J. Appl. Poult. Res. 9:149-155.

Frucht, D. M., T. Fukao, C. Bogdan, H. Schindler, J. J. O'Shea, and S. Koyasu. 2001. IFN-gamma production by antigen-presenting cells: Mechanisms emerge. Trends Immunol. 22:556-560.

Fujiwara, K., M. Yamazaki, H. Abe, K. Nakashima, Y. Yakabe, M. Otsuka, Y. Ohbayashi, Y. Kato, K. Namai, A. Toyoda, Y. Miyaguchi, and Y. Nakamura. 2009. Effect of Bacillus subtilis var. natto fermented soybean on growth performance, microbial activity in the caeca and cytokine gene expression of domestic meat type chickens. Jpn. Poult. Sci. 46:116-122.

Guo, X., D. F. Li, W. Q. Lu, X. S. Piao, and X. L. Chen. 2006. Screening of Bacillus strains as potential probiotics and subsequent confirmation of the in vivo effectiveness of Bacillus subtilis MA139 in pigs. Antonie Van Leeuwenhoek 90:139-146.
He, F., H. Morita, A. Kubota, A. C. Ouwehand, M. Hosoda, M. Hiramatsu, and J. Kurisaki. 2005. Effect of orally administered nonviable Lactobacillus cells on murine humoral immune responses. Microbiol. Immunol. 49:993-997.

Holzapfel, W. H., P. Haberer, R. Geisen, J. Björkroth, and U. Schillinger. 2001. Taxonomy and important features of probiotic microorganisms in food and nutrition. Am. J. Clin. Nutr. 73(Suppl.):365S-373S.

Inooka, S. 1988. The effect of Bacillus natto feed on $\mathrm{H}_{2} \mathrm{O}_{2}$-production function from chicken spleen adherent cells. Tohoku J. Agric. Res. $38: 17-20$.

Jenny, B. F., H. J. Vandijk, and J. A. Collins. 1991. Performance and fecal flora of calves fed a Bacillus subtilis concentrate. J. Dairy Sci. 74:1968-1973.

Kaburagi, T., T. Yamano, Y. Fukushima, H. Yoshino, N. Mito, and K. Sato. 2007. Effect of lactobacillus johnsonii La1 on immune function and serum albumin in aged and malnourished aged mice. Nutrition 23:342-350.

Kosaka, T., T. Maeda, Y. Nakada, M. Yukawa, and S. Tanaka. 1998. Effect of Bacillus subtilis spore administration on activation of macrophages and natural killer cells in mice. Vet. Microbiol. $60: 215-225$.

Kritas, S. K., and R. B. Morrison. 2005. Evaluation of probiotics as a substitute for antibiotics in a large pig nursery. Vet. Rec. 156:447-448.

Ladics, G. S., M. P. Holsapple, J. D. Astwood, I. Kimber, L. M. Knippels, R. M. Helm, and W. Dong. 2003. Workshop overview: Approaches to the assessment of the allergenic potential of food from genetically modified crops. Toxicol. Sci. 73:8-16.

Miettinen, M., J. Vuopio-Varkila, and K. Varkila. 1996. Production of human tumor necrosis factor alpha, interleukin-6, and interleukin-10 is induced by lactic acid bacteria. Infect. Immun. 64:54035405.

Novelli, A., A. Ulivelli, E. F. Reali, F. Mannelli, L. Trombi Belcari, R. Spezia, and P. Periti. 1984. Bacillus subtilis spores as a natural pro-host oral agent. Preliminary data in children. Chemioterapia $3: 152-155$.

Omura, K., M. Hitosugi, X. Zhu, M. Ikeda, H. Maeda, and S. Tokudome. 2005. A newly derived protein from Bacillus subtilis natto with both antithrombotic and fibrinolytic effects. J. Pharmacol. Sci. 99:247-251.

Samanya, M., and K. Yamauchi. 2002. Histological alterations of intestinal villi in chicken fed dried Bacillus subtilis var. natto. Comp. Biochem. Physiol. A 133:95-104.

Scharek, L., J. Guth, K. Reiter, K. D. Weyrauch, D. Taras, P. Schwerk, P. Schierack, M. F. G. Schmidt, L. H. Wieler, and K. Tedin. 2005. Influence of a probiotic Enterococcus faecium strain on development of the immune system of sows and piglets. Vet. Immunol. Immunopathol. 105:151-161.

Shih, I.-L., Y.-T. Yu, C.-J. Shieh, and C.-Y. Hsieh. 2005. Selective production and characterization of levan by Bacillus subtilis (Natto) Takahashi . J. Agric. Food Chem. 53:8211-8215.

Snapper, C. M., and W. E. Paul. 1987. Interferon- $\gamma$ and B cell stimulatory factor-1 reciprocally regulate Ig isotype production. Science 236:944-947.

Solis Pereyra, B., and D. Lemonnier. 1993. Induction of human cytokines by bacteria used in dairy foods. Nutr. Res. 13:1127-1140.

Tejada-Simon, M. V., J. H. Lee, Z. Ustunol, and J. J. Pestka. 1999 Ingestion of yogurt containing Lactobacillus acidophilus and Bifidobacterium to potentiate immunoglobulin A responses to cholera toxin in mice. J. Dairy Sci. 82:649-660.

Teo, A. Y. L., and H. M. Tan. 2005. Inhibition of Clostridium perfringens by a novel strain of Bacillus subtilis isolated from the gastrointestinal tracts of healthy chickens. Appl. Environ. Microbiol. 71:4185-4190.

Yanagisawa, Y., and H. Sumi. 2005. Natto Bacillus contains a large amount of water-soluble vitamin K. J. Food Biochem. 29:267-277. 